\title{
Recusal by the publisher
}

Published online: 28 June 2007

(C) Springer Science + Business Media B.V. 2007

Recusal of "Synthesis of Magnetite Particles with PDLLA Corona" (Jing Tian, Ya Kai Feng and Yong Shen Xu. $J$. Polym. Res. 2006; 13:343-347, DOI: 10.1007/s10965-0069049-7).

The publisher would like to announce that part of this paper has been published previously. The authors have infringed the normal professional ethical codes by plagiarizing another publication: "The Synthesis of Magnetic Core-Shell Nanoparticles by Surface-Initiated Ring-Opening Polymerization of $\varepsilon$-Caprolactone" (Annette M. Schmidt. Macromol. Rapid Commun. 2005; 26:93-97). 